\title{
Rettung aus dem Osten - eine Lösung für Europa?
}

Die europäische Schuldenkrise geht in immer neue Runden. Die Notwendigkeit, ein Marktversagen auf den Bankenmärkten und eine Vertiefung der Wirtschaftskrise zu verhindern, hat viele Staatshaushalte tief in die roten Zahlen getrieben. Einige europäische Länder waren aber auch ohne die Krise von 2008 auf dem Weg zu immer neuen Rekordschuldenständen, weit jenseits der im Stabilitätspakt vereinbarten Schuldengrenze von $60 \%$ des Bruttoinlandsprodukts. Die Investoren hatten der Eurozone zunächst großes Vertrauen entgegengebracht und vor allem den südeuropäischen Mitgliedsländern Finanzierungskonditionen gewährt, die weit günstiger waren als vor der Schaffung der Währungsunion. Nun aber wachsen Zweifel, und die nehmen an Finanzmärkten einen sehr konkreten Ausdruck an: Die Zinsen für die betroffenen Länder steigen.

Damit wird aber ein problematischer Prozess in Gang gesetzt: Je höher die Zinsen sind, desto stärker wachsen auch die Zweifel an der Fähigkeit der Länder, ihren Kapital- und eben auch Zinsdienst zu leisten. Und aus dieser Überlegung ergeben sich neue Zweifel und noch höhere Zinsen. So kann ein sich selbst beschleunigender Prozess entstehen, der, einmal in Gang gekommen, kaum noch aufgehalten werden kann. Die Bonität dieser Länder verschlechtert sich dann nicht mehr allmählich, sondern stürzt schlagartig auf das Konkursniveau ab. Viele Ökonomen unterstellen daher, dass die Finanzkrise ein Problem multipler Gleichgewichte darstellt. Ziel müsse es daher sein, ein gedachtes „Solvenzgleichgewicht“ zu stützen und das „Konkursgleichgewicht" durch gezielte Stützungsmaßnahmen zu entkräften.

Das „Solvenzgleichgewicht“ setzt sich etwa dann gegen das „Konkursgleichgewicht“ durch, wenn die Investoren unendlich geduldig sind und keine Zweifel an der Solvenz des betreffenden Landes entwickeln. Das hervorstechende Beispiel für eine solche Situation ist Japan. Das Land ist weit stärker verschuldet als die europäischen Schuldenstaaten, und dennoch stellen die weitgehend inländischen Investoren dem japanischen Staat die benötigten Mittel zu denkbar günstigen Konditionen zur Verfügung. Nur auf dieser Grundlage kann das Land seine unerhörte Schuldenlast tragen.

Wer könnte der geduldige Investor für Europas Schuldenstaaten sein? Gegenwärtig konstruieren die Europäer einen solchen mit den Stützungskäufen der Europäischen Zentralbank und den Rettungsschirmen. Dahinter stehen die Garantien der anderen Eurostaaten. Diese Garantien scheinen ein Weg zu sein, kostenlos das „Konkursgleichgewicht" zu entkräften, da sie ja bei fortdauernder Solvenz der Schuldenstaaten nie gezogen werden. Die Staaten Europas ziehen sich gewissermaßen selbst am Zopf aus dem Sumpf. Eine verführerische Vorstellung, der ein großer Teil der europäischen Eliten aufgesessen zu sein scheint. Ihr Realitätsgehalt nähert sich allerdings mit weiterem Fortgang der Krise dem der Geschichten des Barons Münchhausen. Denn die Staaten, die diese Hilfe in Anspruch nehmen, präsentieren keineswegs ausgeglichene Haushalte. Ihre Situation verschlechtert sich immer weiter. Die Wahrscheinlichkeit einer Inanspruchnahme aus den Garantien wächst. Damit belasten sie zunehmend die Bonität der Staaten, die für die Werthaltigkeit der Garantien geradestehen. Es droht der oben beschriebene schlagartige Verlust der Kreditwürdigkeit, aber nun auf europäischer Ebene.

Woher also soll das geduldige Geld für die Stabilisierung des "Solvenzgleichgewichts“ kommen, wenn man ein solches „europäisches Armageddon“ nicht riskieren möchte.

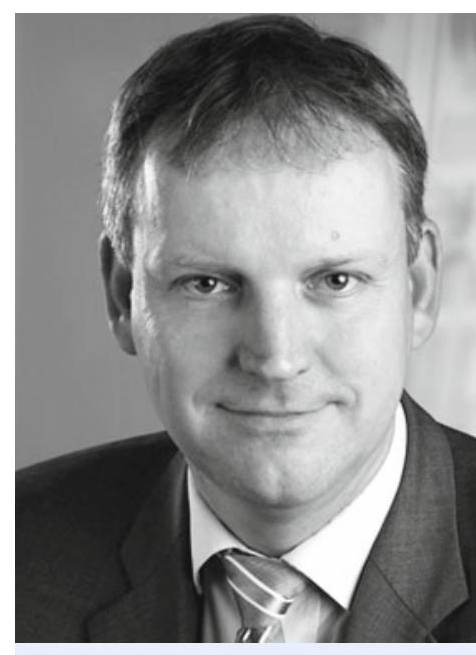

Hans-Peter Burghof ist Professor für Betriebswirtschaftslehre, insbesondere Bankwirtschaft und Finanzdienstleistungen, an der Universität Hohenheim. 
Aus den Schuldenstaaten selbst offenkundig nicht. Im Unterschied zu Japan ist das Kapital der Bürger der europäischen Schuldenstaaten sehr mobil, eine massive Kapitalflucht aus diesen Ländern ist ein weiteres krisenverschärfendes Merkmal.

Es bleibt eine einfache Alternative: Das Geld muss von außen kommen. In den Wachstums- und Rohstoffregionen der Erde haben sich gewaltige Vermögensmassen gebildet, die nach Anlage suchen. Einige dieser Länder, vorneweg die Chinesische Volksrepublik, haben auch schon die Bereitschaft erklärt, zu Hilfe zu kommen und in großem Umfang in europäische Staatsanleihen zu investieren. Hier öffnet sich ein Königsweg zu einer langfristig gesicherten Finanzierung der Eurostaaten, der die kritischen Investoren an den internationalen Kapitalmärkten (oder bösartige spekulative Attacken) nichts mehr anhaben könnten.

Dabei ist schon seit der Antike bekannt: Geschenke sind im zwischenstaatlichen Verkehr nicht zu erwarten. Wer gibt, der nimmt. Wir müssen uns also fragen, welche Interessen hinter einem solchen Engagement etwa der Volksrepublik China stehen, welcher Preis zu zahlen ist. Dazu ist ein genauerer Blick auf den Charakter dieses Investors notwendig. Die Volksrepublik ist ein aus schwersten Geburtswehen entstandener Wirtschaftsgigant. Das 19. und die erste Hälfte des 20. Jahrhunderts waren von einer Abfolge wirtschaftsimperialistischer und militärischer Interventionen verschiedener Staaten in China geprägt, bei denen die Rechte der Menschen und des chinesischen Staates auf das Äußerste missachtet wurden. Eine wesentliche Triebfeder des großen Aufschwungs scheint im Willen zu liegen, nie wieder in eine solche hilflose Lage geraten zu wollen, und in der Erkenntnis, dass China dabei im Zweifel alleine steht, es aber auch alleine schaffen kann. Das resultierende Verständnis des Miteinanders der Staaten ist kompetitiv. Dies kontrastiert mit der Erkenntnis der europäischen Staaten, zwischen den großen Machtblöcken der Welt nur gemeinsam Einfluss und Wohlstand sichern zu können. Für Europa ist dies sicher sinnvoll. Es würde aber von einer großen Kurzsichtigkeit zeugen, würde man dieses kooperative Politikverständnis auch auf unser Verhältnis zu China übertragen. Gute Beziehungen zu China sind wichtig und wertvoll, und Europa war und ist bereit, dafür manchen Preis zu zahlen. Aber man muss wissen, was von dieser Beziehung zu erwarten ist. Sie sollte von Offenheit und Fairness geprägt sein, aber eben nicht von gegenseitiger oder gar einseitiger Abhängigkeit.

Sich auf die Rolle eines geduldigen Investors zu beschränken ist Chinas Sache nicht. Das heutige China ist geprägt durch Dynamik und Ungeduld, den Willen, es hier und jetzt zu schaffen. Dem Geld folgt die Einflussnahme, der Einflussnahme die Machtausübung. Im Miteinander der westlichen Industrienationen haben wir uns daran gewöhnt, dass die Gläubiger der Staaten keine Möglichkeit haben, mit konkreten Machtmitteln auf der Bedienung der Schulden zu bestehen. Die Staaten leisten ihren Schuldendienst vornehmlich, weil sie sich ihren Zugang zum Kapitalmarkt für zukünftige Kreditaufnahmen sichern wollen. Das war nicht immer so, und es muss auch nicht so bleiben. Im 19. Jahrhundert etwa war es durchaus üblich, dass die Staaten ihre politischen und militärischen Machtmittel für die privaten Investitionsinteressen ihrer Bürger einsetzten. Wie viel mehr müssen wir ein solches Engagement bei Investitionen von Staatsfonds erwarten. Welche Formen diese Einflussnahme konkret nehmen wird, bleibt abzuwarten. Aber wir haben es mit einer kommenden Weltmacht zu tun, und da ist Vor- und Weitsicht geboten.

Hans-Peter Burghof

Universität Hohenheim

Hans-Peter.Burghof@uni-hohenheim.de
Sehen wir den Realitäten ins Auge. Niemand wird den exzessiven Konsum und die damit verbundene unseriöse Haushaltspolitik der europäischen Staaten finanzieren, ohne dafür einen hohen Preis zu verlangen. Die Europäer müssen es selbst schaffen, wenn sie keinen Ausverkauf ihrer Interessen und Ideale riskieren wollen. 